\title{
IMPLEMENTASI SUPERVISI OLEH KEPALA SEKOLAH DALAM MENINGKATKAN PROFESIONALISME GURU
}

\author{
Teti Berliani, Rina Wahyuni \\ Email: rinawahyuni33@yahoo.co.id \\ Universitas Palangka Raya, Jalan Yos Sudarso Palangka Jekan Raya Palangka Raya
}

\begin{abstract}
The purpose of this study is to describe the implementation of the supervision by the principal in improving the professionalism of teachers in schools that focus on: (1) the implementation strategy of supervision by the principal in improving the professionalism of teachers in schools; and (2) the obstacles encountered in the implementation of supervision by the principal in improving the professionalism of teachers in schools. This study used a qualitative approach with case study design. The results showed first, strategy implementation supervision by principals in improving the professionalism of teachers in schools include: scheduling carried out regularly in the implementation of supervision; supervision conducted by the principal, vice principal, senior teachers and school supervisors; supervision techniques used more emphasis on techniques classroom visits; and the evaluation of supervision activities that have been done in order to mutually discuss and exchange ideas or opinions in order to improve the process of teaching and learning in schools. And second, the obstacles encountered in the implementation of supervision by principals indicate that: (1) those aspects of concern to the supervisor in the implementation of supervision at the school include uniformity in the preparation of lesson plans, availability of teaching, ways and methods of teaching used by teachers in the teaching and learning process, media conformity lessons with teaching materials are being studied, as well as conditioning active class atmosphere and fun while teaching and learning progress; and (2) the obstacles encountered in the implementation of supervision by the principal, namely: is the fear that a teacher even shy away when they wanted to be supervised, teachers' understanding of the concept of supervision it is still very less because there are still some teachers who think that supervision is rated as the force everything that is desired by the supervisor of the teachers, the provision of follow-up of the school principal it is still not maximized because the workload reason principals outside school hours, as well as the lack of principals to provide encouragement and motivation for teachers especially in preparing teachers to be supervised.
\end{abstract}

Keywords: supervision, teacher professionalism

Abstrak: Tujuan penelitian ini adalah untuk mendeskripsikan tentang implementasi supervisi oleh kepala sekolah dalam meningkatkan profesionalisme guru di sekolah yang berfokus pada: (1) strategi implementasi supervisi oleh kepala sekolah dalam meningkatkan profesionalisme guru di sekolah; dan (2) kendala yang dihadapi dalam implementasi supervisi oleh kepala sekolah dalam meningkatkan profesionalisme guru di sekolah. Penelitian ini menggunakan pendekatan kualitatif dengan rancangan studi kasus. Hasil penelitian menunjukkan pertama, strategi implementasi supervisi oleh kepala sekolah dalam meningkatkan profesionalisme guru di sekolah meliputi: penjadwalan yang dilakukan secara teratur dalam pelaksanaan supervisi; supervisi dilaksanakan oleh kepala sekolah, wakil kepala sekolah, guru-guru senior dan pengawas bidang studi di sekolah; teknik supervisi yang digunakan lebih menekankan pada teknik kunjungan kelas; dan adanya evaluasi terhadap kegiatan supervisi yang telah dilakukan guna saling berdiskusi dan bertukar pikiran atau pendapat dalam rangka perbaikan terhadap proses belajar mengajar di sekolah. Dan kedua, kendala yang dihadapi dalam implementasi supervisi oleh kepala sekolah menunjukkan bahwa: (1) aspek-aspek yang menjadi perhatian supervisor dalam pelaksanaan supervisi di sekolah meliputi keseragaman dalam penyusunan rencana pembelajaran, ketersediaan perangkat mengajar, cara dan metode mengajar yang digunakan guru dalam kegiatan pembelajaran, kesesuaian media pelajaran dengan materi ajar yang sedang dipelajari, serta pengkondisian suasana kelas yang aktif dan menyenangkan saat kegiatan pembelajaran berlangsung; serta (2) kendala yang dihadapi 


\begin{abstract}
dalam pengimplementasian supervisi oleh kepala sekolah, yakni: masih adanya rasa takut yang dimiliki oleh guru bahkan menghindar ketika hendak disupervisi, pemahaman guru mengenai konsep supervisi dirasa masih sangat kurang karena masih ada sebagian guru yang beranggapan bahwa supervisi dinilai sebagai kegiatan memaksa segala sesuatu yang dikehendaki oleh supervisor terhadap guru, pemberian tindak lanjut dari kepala sekolah dirasa masih belum maksimal karena alasan kesibukan kepala sekolah di luar jam sekolah, serta kurangnya kepala sekolah dalam memberikan semangat dan motivasi bagi guru-guru terlebih dalam mempersiapkan diri guru untuk disupervisi.
\end{abstract}

Kata kunci: supervisi, profesionalisme guru

Titik berat pembangunan pendidikan pada era sekarang ditekankan pada peningkatan mutu. Konsekuensinya, perlu adanya peningkatan mutu dari keseluruhan komponen yang terdapat dalam sistem pendidikan, baik itu yang bersifat human resources maupun yang bersifat material resources. Peningkatan keseluruhan komponen sistem pendidikan yang bersifat human resources dan material resources tersebut dapat diartikan dari segi kuantitasnya maupun kualitasnya. Berbagai upaya dalam peningkatan kualitas komponen sistem pendidikan secara keseluruhan mengarah pada pencapaian tujuan pendidikan. Secara operasional, pendidikan dijalankan dalam panduan orientasi utama untuk menyentuh aspekaspek penting yang melekat satu dalam diri manusia, yakni kognitif, afektif dan psikomotorik. Disadari sepenuhnya, bahwa peningkatan kualitas komponen-komponen sistem pendidikan yang terbukti lebih berpengaruh terhadap peningkatan mutu pendidikan adalah komponen yang bersifat human resources. Hal ini dapat dipahami dari kenyataan, bahwa komponen yang bersifat material resources tidak dapat bermanfaat tanpa adanya komponen yang bersifat human resources. Komponen-komponen sistem pendidikan yang bersifat human resources sebenarnya dapat digolongkan menjadi tenaga kependidikan guru dan nonguru.

Diantara komponen-komponen sistem pendidikan yang bersifat human resources, yang selama ini mendapatkan perhatian lebih banyak adalah tenaga guru. Dominannya perhatian pemerintah, dalam hal ini adalah Kementerian Pendidikan dan Kebudayaan terhadap guru sebenarnya didasarkan atas suatu anggapan bahwa ditangan gurulah mutu pendidikan kita bergantung. Hal ini dapat dipahami dari kenyataan bahwa tidak berdayanya sekolah-sekolah bila tidak memiliki guru. Guru dipandang sebagai faktor kunci karena ia yang berinteraksi secara langsung dengan muridnya dalam proses belajar mengajar. Seperti yang dikemukakan oleh Imron (2011), bahwa peran guru yakni sebagai: (1) agen pembaruan; (2) berperan sebagai fasilitator yang memungkinkan terciptanya kondisi yang baik dari segi subjek didik untuk belajar; (3) bertanggung jawab atas terciptanya hasil belajar subjek didik; (4) dituntut menjadi contoh subjek didik; (5) bertanggung jawab secara professional meningkatkan kemampuannya; serta menjunjung tinggi kode etik profesionalnya.

Guru adalah salah satu faktor penting dalam penyelenggaraan pendidikan di sekolah. Oleh karena itu, meningkatkan mutu pendidikan, berarti juga meningkatkan mutu guru. Meningkatkan mutu guru bukan hanya dari segi kesejahteraannya, tetapi juga profesionalitasnya. Undang-undang Nomor 14 Tahun 2005 tentang Guru dan Dosen menyatakan bahwa guru adalah pendidikan profesional dengan tugas utama mendidik, mengajar, membimbing, mengarahkan, melatih, menilai dan mengevaluasi peserta didik pada pendidikan anak usia dini jalur pendidikan formal, pendidikan dasar dan pendidikan menengah. Sebagai seorang professional, guru harus memiliki kompetensi keguruan yang cukup. Kompetensi keguruan itu tampak pada kemampuannya menerapkan sejumlah konsep, asas kerja sebagai guru, mampu mendemonstrasikan sejumlah strategi maupun pendekatan pengajaran yang menarik dan interaktif, disiplin, jujur, dan konsisten.

Guru memiliki potensi yang tinggi untuk berkreasi dan meningkatkan kinerja, namun banyak faktor yang menghambat mereka dalam mengembangkan berbagai potensinya secara optimal. Oleh karena itu, perlu adanya pembinaan kontinu dan berkesinambungan dengan program yang terarah dan sistematis terhadap para guru 
dan personel pendidikan lain di sekolah. Salah satu program pembinaan yang dapat diberikan kepada guru dan personel pendidikan lainnya di sekolah yaitu melalui supervisi. Sahertian (2008) menegaskan bahwa supervisi merupakan usaha mengawali, mengarahkan, mengkoordinasi, membimbing, secara kontinu pertumbuhan guru-guru di sekolah, baik secara individual maupun secara kolektif, agar lebih mengerti dan lebih efektif dalam mewujudkan seluruh fungsi pengajaran, sehingga guru dapat menstimulasi dan membimbing pertumbuhan tiap murid secara kontinu agar dapat lebih cepat berpartisipasi dalam masyarakat demokrasi modern.

Sejalan dengan itu, Mulyasa (2013) menegaskan bahwa dalam supervisi terkandung beberapa kegiatan pokok, yaitu pembinaan yang kontinu, pengembangan kemampuan professional personel, perbaikan situasi belajar mengajar, dengan sasaran akhir pencapaian tujuan pendidikan dan pertumbuhan pribadi peserta didik. Dari beberapa pengertian tersebut menujukkan bahwa supervisi bukanlah kegiatan sesaat seperti inspeksi yang penekanannya hanya kepada mencari kesalahan-kesalahan yang dilakukan oleh guru; melainkan kegiatan pembinaan yang kontinu dan berkesinambungan sehingga guru-guru selalu berkembang dalam mengerjakan tugas dan mampu memecahkan berbagai masalah pendidikan dan pengajaran secara efektif dan efisien. Learning is the main core of the educational services provided by schools to students (Gunawan, 2017).

Akan tetapi, banyak problema-problema yang dihadapi dalam pengimplementasian supervisi di sekolah, antara lain: (1) masih sering ditemukan guru-guru yang takut untuk disupervisi; (2) kurangnya pemahaman guru yang masih menganggap supervisi sebagai kegiatan menilai (mengevaluasi) kinerja guru; (3) guru juga masih menganggap bahwa supervisi sebagai kegiatan mencari-cari kesalahan guru di kelas (inspeksi); (4) kegiatan supervisi sejawat yang dilakukan oleh rekan kerja (guru senior) terhadap guru junior yang bisa dikatakan masih bersifat memaksakan apa yang dikehendaki oleh guru senior; (5) supervisor seringkali tidak konsekuen dalam membuat tindak lanjut pelaksanaan supervisi terhadap guru-guru; serta (6) kurangnya ketegasan dari kepala sekolah dalam hal pemberian supervisi kepada para guru.
Menilik dari beberapa problema tersebut, tentu sangat bertolak belakang dengan pentingnya pengimplementasian supervisi tersebut dalam membantu guru-guru agar menjadi lebih baik terutama dalam hal pengajaran di kelas. Selain itu, banyak sekali manfaat yang didapatkan melalui pelaksanaan supervisi, antara lain: (1) guru dapat mengetahui kelebihan dan kelemahannya dalam proses belajar mengajar di sekolah; (2) guru menjadi lebih kreatif dan inovatif dalam mengembangkan metode dan strategi yang digunakan dalam pembelajaran; (3) guru menjadi lebih mengerti dan menguasai peralatan serta perlengkapan dalam menunjang pembelajaran; (4) guru dituntut untuk bisa mengenali sumber-sumber belajar yang relevan dan mengikuti perkembangan zaman; serta (5) guru dapat berkolaborasi dengan rekan sejawat baik dengan rekan guru junior maupun guru senior dalam berdiskusi dan berbagi pengalaman teruntuk memperbaiki pelaksanan belajar mengajar (PBM). Supervisi dilaksanakan untuk meningkatkan mutu pembelajaran dan pengembangan profesionalisme guru (Gunawan, 2015c).

Sejalan dengan itu, jika dikaitkan dengan kompetensi-kompetensi yang harus dimiliki oleh guru, maka salah satu kompetensi yang perlu mendapatkan perhatian adalah kompetensi professional. Sebagaimana tercantum dalam Undang-undang Nomor 14 tahun 2005 tentang Guru dan Dosen yang menegaskan bahwa profesional adalah pekerjaan atau kegiatan yang dilakukan oleh seseorang dan menjadi sumber penghasilan kehidupan yang memerlukan keahlian, kemahiran,atau kecakapan yang memenuhi standar mutu atau norma tertentu serta memerlukan pendidikan profesi. Seperti halnya pernyataan tersebut, Masaong (2013) juga menyebutkan bahwa guru yang professional harus mampu dalam: (1) menguasai materi, struktur, konsep dan pola pikir keilmuan, yang mendukung mata pelajaran yang diampu; (2) menguasai standar kompetensi dan kompetensi dasar mata pelajaran/bidang pengembangan yang diampu; (3) mengembangkan materi pelajaran yang diampu secara kreatif; (4) mengembangkan keprofesionalan secara berkelanjutan dengan melakukan tindakan reflektif; dan (5) memanfaatkan teknologi informasi dan komunikasi dan mengembangkan diri. 
Pendidikan akan bermutu jika sesuai dengan apa yang diharapkan oleh masyarakat (benchmark) dapat dipenuhi. Apabila suatu sekolah telah mencapai standar mutu yang dipersyaratkan, maka sekolah tersebut secara bertahap mampu mencapai mutu yang kompetitif baik yang bertaraf nasional maupun bertaraf internasional. Peningkatan mutu akan dapat dipenuhi, jika pembinaan sumber daya manusia terjaga kualitas profesionalnya. Kemudian perlu diterapkan pengawasan yang intensif, agar semua pelaksanaan program dan kegiatan dapat memenuhi standard dan pencapaiannya terukur. Pengawasan dan kontrol yang terukur dapat dilakukan dengan melaksanakan kegiatan supervisi baik yang dilakukan oleh pengawas sekolah, kepala sekolah, sejawat guru, dan stakeholders lainnya.

\section{METODE}

Penelitian ini menggunakan pendekatan kualitatif dengan rancangan studi kasus. Studi kasusinipadahakikatnyamenelitikasus, manakala kasus tersebut diperlukan dan penting untuk "menguji" suatu teori yang telah tersusun dengan baik. Studi kasus juga dimaknai kasus organisasi, yaitu studi kasus untuk mendapatkan informasi tentang keterangan-keterangan organisasi dimana peneliti ingin mengetahui bagaimana kehidupan orang-orang dalam organisasi tersebut. Penentuan informan dilakukan dengan teknik pengambilan sampel secara purposive sampling dan snowball sampling. Pemilihan informan dengan menggunakan purposive dan snowball sampling diperuntukkan agar diperoleh data dan informasi dari orang-orang yang benarbenar mengetahui secara mendalam terkait fokus penelitian sehingga data yang diterima dapat lebih akurat. Dari informan pertama, maka akan berkembang ke informan kedua dan seterusnya sehingga diibaratkan seperti bola salju.

Hal itu sejalan dengan yang dikatakan oleh Ulfatin (2014), begitu informan kunci pertama diwawancarai secukupnya, ia diminta untuk menunjukkan satu atau lebih sumber lain yang dianggapnya memiliki informasi yang dianggap relevan dan memadai, sehingga dapat dijadikan sebagai informan berikutnya. Dari informan kedua yang ditunjuk oleh informan pertama, kemudian ia diminta untuk menyebutkan sumber lain yang dapat dijadikan informan berikutnya lagi. Dengan cara inilah, informasi yang diperoleh peneliti menjadi semakin besar dengan melibatkan beberapa orang yang menurut Bogdan dan Biklen (1992) diibaratkan seperti bola salju (snowball sampling). Teknik pengumpulan data yang digunakan adalah: (1) observasi; (2) wawancara mendalam; dan (3) studi dokumentasi.

Datayangterkumpuldariketigatekniktersebut dianalisis secara berulang dengan menggunakan alur pola interaktif analisis data penelitian Miles dan Huberman (2011) yang meliputi reduksi data, penyajian data, dan penarikan kesimpulan. Pengecekan kredibilitas data dilakukan dengan teknik triangulasi (sumber dan teknik/metode), member checks, dan kecukupan bahan referensi; pengecekan dependabilitas data penelitian dilakukan oleh peneliti mulai dari melakukan penelitian, penyusunan transkrip wawancara sampai dengan penulisan laporan hasil penelitian dan pelaksanaan penelitian sesuai dengan jadwal yang telah disepakati bersama; dan pengecekan konfirmabilitas digunakan untuk melihat bahwa hasil penelitian yang dilakukan menunjukkan adanya proses penelitian di lapangan.

\section{HASIL}

Penelitian ini mengeskplorasi strategi dan kendala yang dihadapi dalam implementasi supervisi oleh kepala sekolah dalam meningkatkan profesionalisme guru di sekolah. Strategi implementasi supervisi oleh kepala sekolah dalam meningkatkan profesionalisme guru di sekolah menunjukkan: (1) pelaksanaan kegiatan supervisi dilakukan secara terjadwal yakni dilaksanakan dua kali dalam tiap semester dengan rentang waktu per tiga bulan sekali yang dimulai di awal semesteran, yang disusun oleh wakil kepala sekolah bidang kurikulum; (2) kegiatan supervisi di sekolah dilakukan oleh pengawas sekolah, kepala sekolah, wakil kepala sekolah dan para guru senior; (3) teknik supervisi yang digunakan dalam pengimplementasian supervisi yaitu teknik secara individu yang meliputi kunjungan kelas dan observasi kelas; dan (4) proses evaluasi kegiatan supervisi yang dilakukan di sekolah berupa pemberian respons/ 
tanggapan langsung terhadap guru-guru yang telah disupervisi, serta evaluasi yang dilakukan saat rapat bersama antara kepala sekolah, wakil kepala sekolah, dan semua guru.

Evaluasi yang diberikan biasanya berupa pemberitahuan tentang kelebihan yang telah dimiliki guru dalam melaksanakan proses belajar mengajar di kelas kemudian juga berkenaan dengan kelemahan guru saat mengajar yang perlu mendapatkan perhatian agar dilakukannya perbaikan menuju ke arah yang lebih baik. Sedangkan kendala yang dihadapi dalam implementasi supervisi oleh kepala sekolah dalam meningkatkan profesionalisme guru di sekolah menunjukkan: (1) aspek-aspek yang menjadi perhatian supervisor dalam melaksanakan supervisi di sekolah meliputi: keseragaman dalam penyusunan/pembuatan rencana pelaksanaan pembelajaran (RPP); ketersediaan perangkat mengajar; cara dan metode mengajar yang digunakan guru dalam menyampaikan pelajaran di kelas; kesesuaian media pelajaran yang digunakan guru dalam menyampaikan pembelajaran; serta pengkondisian suasana kelas yang aktif dan menyenangkan saat PBM berlangsung; dan (2) kendala yang dialami saat melaksanakan supervisi di sekolah, meliputi: adanya rasa takut bahkan menghindar yang dimiliki beberapa orang guru ketika hendak disupervisi; pemahaman guru tentang konsep supervisi yang sebenarnya dirasa masih sangat kurang; ketidakkonsekuenan kepala sekolah dalam memberikan tindak lanjut dari kegiatan supervisi karena kesibukan yang dimiliki kepala sekolah; serta kelalaian kepala sekolah dalam memberikan semangat dan motivasi bagi guru-guru dalam mempersiapkan diri untuk disupervisi.

Hasil penelitian di atas menunjukkan bahwa kegiatan supervisi yang ada di sekolah sudah dilaksanakan secara terjadwal yakni dua kali dalam satu semester; dan dalam pelaksanaan supervisi tersebut dilakukan oleh kepala sekolah, wakil kepala sekolah, guruguru senior dan pengawas bidang studi yang ada di sekolah. Hasil penelitian tentang teknik yang digunakan dalam melakukan supervisi di sekolah menunjukkan bahwa supervisor lebih menggunakan teknik yang bersifat individual, yakni kunjungan kelas. Teknik kunjungan kelas menjadi salah satu teknik yang dianggap paling efektif dalam pelaksanaan kegiatan supervisi; karena dengan kunjungan kelas, para supervisor dapat melihat secara langsung kegiatan belajar mengajar guru di dalam kelas sehingga supervisor dapat mengamati dengan jelas kelebihan dan kelemahan dari guru yang sedang disupervisinya.

\section{PEMBAHASAN}

Penyusunan program supervisi harusnya disusun untuk masa waktu selama satu tahun ajaran (Muslim, 2013). Oleh karena itu, dalam pengimplementasiannya diperlukan suatu rencana kegiatan yang lebih spesifik yang diprogramkan secara caturwulan atau semester, program bulanan dan program mingguan. Sehingga akan memberikan kejelasan tentang apa yang harusnya dilakukan supervisor dalam upaya mengimplementasikan program supervisi untuk masa waktu tertentu. Sutisna (1989) menyatakan supervisi sebagai suatu bentuk pelayanan, bantuan profesional, atau bimbingan bagi guru-guru dan dengan melalui pertumbuhan kemampuan guru hendaknya meningkatkan mutu pendidikan dan pengajaran. Lebih lanjut Sutisna menjelaskan berbagai aspek supervisi dilakukan oleh mereka yang disebut pengawas, penilik, dan kepala sekolah, atau setiap jabatan atau kedudukan lain yang diberi tanggungjawab tentang kegiatan-kegiatan yang bersifat supervisi.

Hal lain yang tidak kalah penting dalam strategi pengimplementasian supervisi yang dilakukan oleh kepala sekolah dalam meningkatkan profesionalisme guru yakni evaluasi terhadap kegiatan supervisi yang telah dilaksanakan. Evaluasi terhadap kegiatan supervisi ini dilakukan untuk mengetahui tingkat keberhasilan dari kegiatan supervisi itu sendiri; maksudnya di sini adalah tingkat keberhasilan yang dilihat dari berbagai aspek yang menunjang dalam proses belajar mengajar, baik itu dari segi personal (guru dan siswa), sarana prasarana penunjang kegiatan belajar mengajar (KBM) dan dari segi pelaksanaan KBM (operasional). Sejalan dengan itu, Burhanuddin, dkk., (2007) mengungkapkan evaluasi kegiatan supervisi berusaha menentukan sampai seberapa jauh tujuan supervisi telah tercapai. Bahkan ruang 
lingkup evaluasi kegiatan supervisi menyangkut semua komponen yang terkait dalam pelaksanaan supervisi, yang meliputi: aspek personal, aspek material, dan aspek operasional supervisi.

Elsbree, dkk., (1967) mengatakan an important characteristic of modern supervision is its emphasis on evaluation, including evaluation of the teacher and the school's program. McNerney (1951) menegaskan bahwa the purpose of any program of evaluation is to discover the needs of the individuals being evaluated and than to design learning experiences the will satisfy these needs. Supervisi pengajaran merupakan serangkaian usaha bantuan kepada guru secara profesional (Gunawan, 2015a). Supervisi bertujuan mengembangkan situasi kegiatan pembelajaran yang lebih baik untuk mencapai tujuan pendidikan sekolah, membina guru secara profesional, dan membantu guru dalam menilai hasil belajar siswa (Gunawan, 2011). Hasil penelitian Gunawan (2014b) menyimpulkan terdapat pengaruh yang signifikan supervisi pengajaran dan kemampuan guru mengelola kelas guru terhadap motivasi belajar siswa. Oleh sebab itu, supervisor harus membimbing dan mengarahkan guru secara profesional dalam hal persiapan, pelaksanaan, pelaporan, dan perbaikan pembelajaran (Gunawan, 2014b). Supervisi pengajaran diarahkan untuk mengembangkan proses pembelajaran yang dilakukan oleh guru (Gunawan, 2014a). Kepala sekolah dan supervisor dalam memberikan pembinaan profesional kepada guru sebaiknya menerapkan sifat-sifat kepemimpinan pendidikan (Gunawan, 2015b).

Burhanuddin, dkk., (2007) menyatakan melalui evaluasi supervisi ini, supervisor dapat: (1) memperbaiki praktik-praktik pengajaran; (2) memberikan dorongan peningkatan PBM di sekolah; serta (3) memberikan pertimbangan dan saran atas peningkatan pengelolaan sarana dan prasarana penunjang PBM di sekolah. Pidarta (2009) menegaskan bahwa sebagai kegiatan membina para pendidik dalam mengembangkan proses pembelajaran, termasuk segala unsur penunjangnya. Hal yang perlu diperhatikan dan dikembangkan pada diri setiap guru oleh kepala sekolah sebagai supervisor adalah: (1) kepribadian guru; (2) peningkatan profesi secara kontinu; (3) proses pembelajaran; (4) penguasaan materi pelajaran; (5) keragaman kemampuan guru; (6) keragaman daerah; dan (7) kemampuan guru dalam bekerja sama dengan masyarakat. Hal senada dikemukakan oleh Gaffar (1992) yang menyatakan tugas supervisor adalah membantu guru-guru dalam mencari penyelesaian masalah yang berhubungan dengan motivasi kerja, metode mengajar guru, pelaksanaan kurikulum, serta teknik evaluasi pengajaran yang digunakan oleh guru.

Terlebih dalam pelaksanaan supervisi, ada supervisor yang masih menerapkan kegiatan supervisi yang bersifat inspeksi, yaitu coercive supervision; dimana dalam pelaksanaan supervisinya, supervisor bersifat memaksakan segala sesuatu yang dianggapnya benar dan baik menurut pendapatnya sendiri. Hal itu sangat bertolak belakang dengan pendapat Gaffar (1992) yang menegaskan tugas seorang supervisor adalah membimbing dan menolong guru-guru serta karyawan-karyawan pendidikan lainnya dalam perbaikan-perbaikan pendidikan; supervisor harus memberikan dorongan dan semangat kepada guru-guru dalam lapangan tugasnya; supervisor harus melakukan penyeleksian dan perbaikan-perbaikan dalam tujuan pengajaran, metoda mengajar, dan evaluasi pengajaran serta kegiatan-kegiatan perbaikan kurikulum dan tujuan pendidikan. Supervisor memiliki kewajiban untuk membina kemampuan para guru secara profesional (Gunawan, 2014a).

Hal senada dikemukakan oleh Sutisna (1989) yang menyatakan bahwa supervisi didasarkan pada kerja sama, tidak pada paksaan atau ancaman. Purwanto (2007) menegaskan supervisi bukan lagi suatu pekerjaan yang dipegang oleh seorang petugas, melainkan pekerjaan-pekerjaan bersama yang dikoordinasikan. Tanggung jawab tidak dipegang sendiri oleh supervisor, melainkan dibagi-bagikan kepada para anggota sesuai dengan tingkat, keahlian dan kecakapannya masing-masing. Karena supervisi merupakan usaha dari para pejabat sekolah yang diangkat dan diarahkan kepada penyediaan kepemimpinan bagi para guru dan tenaga pendidikan lain dalam perbaikan pengajaran; melibat stimulasi pertumbuhan profesional dan perkembangan dari para guru, seleksi dan revisi tujuan-tujuan pendidikan, bahan pengajaran dan metodemetode mengajar dan evaluasi pengajaran. Tugas 
dan peran guru bukan saja mendidik, mengajar, dan melatih saja, tetapi juga bagaimana guru juga dapat membaca situasi kelas dan kondisi siswanya dalam menerima pelajaran (Gunawan, 2016).

Muslim (2013) mengungkapkan kunjungan kelas adalah kunjungan yang dilakukan oleh supervisor (kepala sekolah) ke kelas pada saat guru sedang mengajar; dan melalui kunjungan kelas, supervisor dapat mengetahui aktivitas guru dan siswa dan permasalahan-permasalahan yang mereka hadapi dalam melaksanakan KBM, yang mana informasi tersebut sangatlah penting artinya bagi supervisor dalam upaya membantu guru meningkatkan kemampuan profesionalnya. Burhanuddin, dkk., (2007) menegaskan kunjungan kelas dan pengamatan kelas yang dilaksanakan oleh kepala sekolah atau pengawas sekolah bermanfaat untuk mengetahui kualitas pelaksanaan kegiatan proses belajar mengajar. Lebih lanjut Burhanuddin, dkk., (2007) juga menjelaskan, selama kunjungan kelas kepala sekolah dan pengawas dapat: (1) mempelajari kekuatan dan kelemahan pelaksanaan kegiatan pembelajaran untuk pengembangan dan pembinaan lebih lanjut; (2) mengidentifikasi kendala yang dihadapi sewaktu melaksanakan suatu gagasan pembaharuan pengajaran; (3) secara langsung mengetahui keperluan guru dan siswa dalam melaksanakan proses belajar mengajar yang efektif; (4) memperoleh sejumlah informasi untuk menyusun program pembinaan professional secara terinci; serta (5) menumbuhkan sikap percaya diri guru untuk berbuat dan melaksanakan pembelajaran yang lebih baik.

Sahertian (2008) mengemukakan teknik kunjungan kelas merupakan salah satu teknik dalam pelaksanaan supervisi dimana kepala sekolah atau supervisor datang ke kelas untuk melihat cara guru mengajar di kelas. Lebih lanjut Sahertian (2008) menegaskan tujuan menggunakan teknik kunjungan kelas yaitu supervisor dapat memperoleh data mengenai keadaan sebenarnya selama guru mengajar. Dengan data itu, supervisor dapat berbincangbincang dengan guru tentang kesulitan yang dihadapi guru-guru. Pada kesempatan itu pula, guru-guru dapat mengemukakan pengalamanpengalaman yang berhasil dan hambatanhambatan yang dihadapi dan meminta bantuan, dorongan, dan mengikutsertakan. Bantuan pembinaan profesional supervisor kepada guru, sangat berarti bagi guru, sebab dewasa ini guru dihadapkan pada pada tuntutan yang semakin berat, terutama untuk mempersiapkan siswa agar mampu menghadapi dinamika perubahan yang berkembang dengan pesat (Gunawan, 2013). Supervisi pengajaran bertujuan untuk membina guru secara profesiona, dan guru yang profesional diharapkan memberikan kontribusi yang besar terhadap peningkatan mutu pendidikan (Gunawan, 2009).

\section{KESIMPULAN DAN SARAN}

\section{Kesimpulan}

Strategi implementasi supervisi oleh kepala sekolah guna meningkatkan profesionalisme guru dikategorikan cukup baik. Hal ini dapat dilihat dari: (1) pelaksanaan supervisi sudah dilakukan secara terjadwal yakni dua kali dalam setiap semester; (2) pelaksana kegiatan supervisi juga tidak hanya dilakukan oleh kepala sekolah tetap dilakukan juga oleh wakil kepala sekolah, guru-guru senior, dan para pengawas bidang studi di sekolah; (3) teknik supervisi yang digunakan adalah teknik individual dengan melakukan kunjungan kelas saat guru sedang melaksanakan PBM; serta (4) adanya evaluasi terhadap kegiatan supervisi yang telah dilakukan guna saling berdiskusi dan bertukar pikiran/pendapat dalam rangka perbaikan terhadap proses belajar mengajar di sekolah.

Kendala yang dihadapi dalam implementasi supervisi oleh kepala sekolah guna meningkatkan profesionalisme guru berkaitan dengan: aspekaspek yang menjadi perhatian supervisor dalam pelaksanaan supervisi yaitu keseragaman penyusunan RPP, ketersediaan perangkat mengajar, cara dan metode mengajar yang digunakan guru dalam PBM, kesesuaian media pelajaran dengan materi ajar yang sedang dipelajari, serta pengkondisian suasana kelas yang aktif dan menyenangkan. Kendala yang dihadapi dalam implementasi supervisi oleh kepala sekolah, yakni: masih adanya rasa takut yang dimiliki oleh guru bahkan menghindar ketika hendak disupervisi; pemahaman guru mengenai konsep supervisi dirasa masih sangat kurang karena ada sebagian guru yang beranggapan bahwa supervisi dinilai sebagai kegiatan 
memaksa segala sesuatu yang dikehendaki oleh supervisor terhadap guru; pemberian tindak lanjut dari kepala sekolah dirasa masih belum maksimal karena alasan kesibukan kepala sekolah di luar jam sekolah; serta kurangnya kepala sekolah dalam memberikan semangat dan motivasi bagi guru-guru terlebih dalam mempersiapkan diri guru untuk disupervisi.

\section{Saran}

Berdasarkan temuan penelitian, saran yang diajukan bagi Dinas Pendidikan, Pemuda, dan Olahraga Kota Palangka Raya diharapkan dapat dijadikan sebagai bahan masukan dan saran dalam upaya memfasilitasi tiap-tiap sekolah untuk mengembangkan kreatifitas dan inovasi guru-guru dalam meningkatkan profesionalisme yang dimiliki sehingga dapat berdampak pada perkembangan guru-guru dan juga berimbas pada kualitas peserta didik dan kualitas sekolah. Bagi kepala sekolah diharapkan dapat menjadi masukan sebagai pengaplikasian kegiatan supervisi yang lebih baik lagi; karena sebagai seorang supervisor sangatlah dibutuhkan kesiapan yang mampu memberikan pembinaan, dorongan, arahan dan semangat bagi para guruguru untuk terus memperbaiki diri dengan menyesuaikan pada perkembangan zaman yang ada saat ini. Bagi para guru diharapkan agar tidak perlu merasa takut bahkan menghindar ketika akan disupervisi. Guru sebaiknya meminta kepala sekolah untuk melakukan supervisi terhadap kinerjanya, sehingga secara bersama-sama akan tercipta koordinasi yang lebih baik antara guru dan supervisornya dalam melakukan perbaikanperbaikan terutama dalam hal pengajaran.

\section{DAFTAR RUJUKAN}

Bogdan, R. C., dan Biklen, S.K. 1992.

Qualitative Research for Education. New York: Allyn and Bacon.

Burhanuddin, Soetopo, H., Imron, A., Maisyaroh, dan Ulfatin, N. 2007. Supervisi Pendidikan dan Pengajaran: Konsep, Pendekatan, dan Penerapan Pembinaan Profesional. Malang: Fakultas lmu Pendidikan Universitas Negeri Malang.

Elsbree, W. S., McNally, H. J., dan Wynn, R. 1967. Elementary Administration and Supervision. New York: American Book Company.
Gaffar. 1992. Dasar-Dasar Administrasi dan Supervisi Pengajaran. Padang: Angkasa Raya.

Gunawan, I. 2009. Sertifikasi Guru: Antara Harapan dan Kenyataan. Banjarmasin Pos, hlm. 6.

Gunawan, I. 2011. Pendekatan Alternatif dalam Pelaksanaan Supervisi Pengajaran. Premiere Educandum, 1(2), 211-232.

Gunawan, I. 2014a. Analisis Dampak Supervisi Pendidikan terhadap Perkembangan Masyarakat dan Ilmu Pengetahuan dan Teknologi. Prosiding Seminar Nasional Pendidikan Revitalisasi Manajemen Pendidikan Nasional Menuju Perbaikan Mental, Jurusan Administrasi Pendidikan Universitas Negeri Malang, 8-9 Desember, hlm. 249-269.

Gunawan, I. 2014b. Pengaruh Supervisi Pengajaran dan Kemampuan Guru Mengelola Kelas terhadap Motivasi Belajar Siswa. Ilmu Pendidikan Jurnal Kajian Teori dan Praktik Kependidikan, 41(1), 44-52.

Gunawan, I. 2015a. Mengembangkan Alternatifalternatif Pendekatan dalam Pelaksanaan Supervisi Pengajaran. Manajemen Pendidikan, 24(6), 467-482.

Gunawan, I. 2015b. Pengaruh Kepemimpinan Transformasional dan Kepuasan Kerja terhadap Perilaku Kewargaan Organisasi Guru Sekolah Dasar. Premiere Educandum, 5(1), 59-58.

Gunawan, I. 2015c. Optimalisasi Peran dan Tugas Kepala Sekolah dalam Implementasi Kurikulum 2013. Prosiding Seminar Nasional Implementasi Kebijakan Ujian Nasional, Dualisme Kurikulum, dan Sistem Seleksi Masuk Perguruan Tinggi Negeri, Fakultas Ilmu Pendidikan Universitas Negeri Malang, Malang, 15 s.d. 16 Mei, hlm. 2329.

Gunawan, I. 2016. Manajemen Kelas. Malang: UM Press.

Gunawan, I. 2017. Instructional Management in Indonesia: A Case Study. Journal of Arts, Science, and Commerce, 8(1), 99-107.

Imron, A. 2011. Supervisi Pembelajaran Tingkat Satuan Pendidikan. Jakarta: PT Bumi Aksara.

Masaong, A. K. 2013. Supervisi Pembelajaran dan Pengembangan Kapasitas Guru. Bandung: Alfabeta.

McNerney, C. T. 1951. Educational Supervision. New York: McGraw-Hill Book Company, Inc.

Miles, M. B., dan Huberman, A. M. 2011. Analisis Data Kualitatif Buku Sumber tentang Metodemetode Baru. Terjemahan oleh Tjetjep Rohendi Rohidi. Jakarta: UI Press.

Mulyasa, E. 2013. Manajemen dan Kepemimpinan Kepala Sekolah. Jakarta: PT Bumi Aksara. 
Muslim. 2013. Supervisi Pendidikan Meningkatkan Kualitas Profesionalisme Guru. Bandung: Alfabeta.

Pidarta, M. 2009. Supervisi Pendidikan Kontekstual. Jakarta: Rineka Cipta.

Purwanto, N. 2007. Administrasi dan Supervisi Pendidikan. Bandung: Remaja Rosdakarya.

Sahertian, P. A. 2008. Konsep Dasar dan Teknik Supervisi Pendidikan dalam Rangka Pengembangan Sumber Daya Manusia. Jakarta: Rineka Cipta.
Sutisna. 1989. Administrasi Pendidikan Dasar Teoritis untuk Praktek Profesional. Bandung: Angkasa Bandung.

Ulfatin, N. 2014. Metode Penelitian Kualitatif di Bidang Pendidikan: Teori dan Aplikasinya. Malang: Bayumedia Publishing.

Undang-undang Nomor 14 Tahun 2005 tentang Guru dan Dosen. 2006. Bandung: Citra Umbara. 